\title{
SISTEM IMPLEMENTASI UNTUK INVENTASI PADA INDUSTRI OTOMOTIF
}

\author{
Edri Wahyudi \\ 155100022, 785567933 \\ Fakultas Komputer \\ edriwahyudi.student@umitra.ac.id
}

\begin{abstract}
Industri otomotif saat ini berkembang sangat pesat terutama di kota-kota besar, hal ini mengingat kebutuhan alat dalam menjalani kegiatan sehari-hari dengan mobilitas yang sangat tinggi. Brand yang bersaing dalam industry ini juga tidak sedikit, mulai dari kelas premium seperti Mercedes-benz, BMW sampai dengan Honda, Toyota, Daihatsu, dll. Belum lagi Brand baru yang masuk dalam persaingan industry otomotif seperti Proton dan Chery.
\end{abstract}

Industri otomotif memegang peranan penting dalam perekonomian terutama di Indonesia. Saat terjadi krisis global yang berasal dari Amerika pada tahun 2008, industri otomotif bertumbuh positif ketika industri-industri lainnya melambat. Pada pertengahan tahun 2009, industri otomotif di Indonesia kembali bersemangat sehingga penjualan dipastikan terus meningkat dari tahun ke tahun. Sampai pada akhir tahun 2010 penjualan mobil telah mencapai 625ribu unit, mengalahkan rekor pada tahun 2008 angka penjualannya mencapai 603unit. Indonesia bersama Thailand merupakan pasar industry otomotif dalam kawasan ASEAN. Tahun 2008, Thailand menguasai $29 \%$ penjualan mobil di ASEAN, kemudian diikuti Indonesia yang menguasai 28\% pasar. (Investor Daily, 2011) 
Mayoritas pasar otomotif di Indonesia dikuasai oleh mobil berpenumpang atau yang sering kita sebut multi purpose vehicle (MPV), MPV menguasai $75 \%$ penjualan mobil di Indonesia, sisanya adalah mobil seperti sedan dan city car. Berdasarkan Brand, Toyota merupakan market leader dengan menguasai 37,9\% pasar mobil di Indonesia, diikuti Daihatsu 14,7\% dan Mitsubishi 14,1\% pasar mobil. Dalam iklim persaingan industry otomotif seperti ini, Toyota mampu menjadi market leader, hal ini tentu bukan hal yang biasa. PT. Toyota Astra Motor melalui produk Toyota kijang meraih penghargaan indonesian customer loyalty award 2005 untuk kategori mobil non sedan berdasarkan survey indonesian customer loyalty index 2005.

Kata Kunci : Industri Otomotif. 


\section{A. INTRODUCTION}

Industri otomotif saat ini berkembang sangat pesat terutama di kota-kota besar, hal ini mengingat kebutuhan alat dalam menjalani kegiatan sehari-hari dengan mobilitas yang sangat tinggi. Brand yang bersaing dalam industry ini juga tidak sedikit, mulai dari kelas premium seperti Mercedes-benz, BMW sampai dengan Honda, Toyota, Daihatsu, dll. Belum lagi Brand baru yang masuk dalam persaingan industry otomotif seperti Proton dan Chery.

Industri otomotif memegang peranan penting dalam perekonomian terutama di Indonesia. Saat terjadi krisis global yang berasal dari Amerika pada tahun 2008, industri otomotif bertumbuh positif ketika industri-industri lainnya melambat. Pada pertengahan tahun 2009, industri otomotif di Indonesia kembali bersemangat sehingga penjualan dipastikan terus meningkat dari tahun ke tahun. Sampai pada akhir tahun 2010 penjualan mobil telah mencapai 625ribu unit, mengalahkan rekor pada tahun 2008 angka penjualannya mencapai 603unit. Indonesia bersama Thailand merupakan pasar industry otomotif dalam kawasan ASEAN. Tahun 2008, Thailand menguasai $29 \%$ penjualan mobil di ASEAN, kemudian diikuti Indonesia yang menguasai $28 \%$ pasar. (Investor Daily, 2011)

Mayoritas pasar otomotif di Indonesia dikuasai oleh mobil berpenumpang atau yang sering kita sebut multi purpose vehicle (MPV), MPV menguasai $75 \%$ penjualan mobil di Indonesia, sisanya adalah mobil seperti sedan dan city car. Berdasarkan Brand, Toyota merupakan market leader dengan menguasai 37,9\% pasar mobil di Indonesia, diikuti Daihatsu 14,7\% dan Mitsubishi 14,1\% pasar mobil. Dalam iklim persaingan industry otomotif seperti ini, Toyota mampu menjadi market leader, hal ini tentu bukan hal yang biasa. PT. Toyota Astra Motor melalui produk Toyota kijang meraih penghargaan indonesian customer loyalty 
award 2005 untuk kategori mobil non sedan berdasarkan survey indonesian customer loyalty index 2005.

\section{B. CONTENT}

Industri otomotif saat ini berkembang sangat pesat terutama di kota-kota besar, hal ini mengingat kebutuhan alat dalam menjalani kegiatan sehari-hari dengan mobilitas yang sangat tinggi. Brand yang bersaing dalam industry ini juga tidak sedikit, mulai dari kelas premium seperti Mercedes-benz, BMW sampai dengan Honda, Toyota, Daihatsu, dll. Belum lagi Brand baru yang masuk dalam persaingan industry otomotif seperti Proton dan Chery.

Industri otomotif memegang peranan penting dalam perekonomian terutama di Indonesia. Saat terjadi krisis global yang berasal dari Amerika pada tahun 2008, industri otomotif bertumbuh positif ketika industri-industri lainnya melambat. Pada pertengahan tahun 2009, industri otomotif di Indonesia kembali bersemangat sehingga penjualan dipastikan terus meningkat dari tahun ke tahun. Sampai pada akhir tahun 2010 penjualan mobil telah mencapai 625ribu unit, mengalahkan rekor pada tahun 2008 angka penjualannya mencapai 603unit. Indonesia bersama Thailand merupakan pasar industry otomotif dalam kawasan ASEAN. Tahun 2008, Thailand menguasai 29\% penjualan mobil di ASEAN, kemudian diikuti Indonesia yang menguasai 28\% pasar. (Investor Daily, 2011) 
Mayoritas pasar otomotif di Indonesia dikuasai oleh mobil berpenumpang atau yang sering kita sebut multi purpose vehicle (MPV), MPV menguasai $75 \%$ penjualan mobil di Indonesia, sisanya adalah mobil seperti sedan dan city car. Berdasarkan Brand, Toyota merupakan market leader dengan menguasai 37,9\% pasar mobil di Indonesia, diikuti Daihatsu 14,7\% dan Mitsubishi 14,1\% pasar mobil. Dalam iklim persaingan industry otomotif seperti ini, Toyota mampu menjadi market leader, hal ini tentu bukan hal yang biasa. PT. Toyota Astra Motor melalui produk Toyota kijang meraih penghargaan indonesian customer loyalty award 2005 untuk kategori mobil non sedan berdasarkan survey indonesian customer loyalty index 2005 .

“Rahasia kekuatan Toyota adalah bahwa perusahaan memiliki strategi yang andal sejak awal, dan lebih penting lagi, pergantian generasi manajemen senior terus menjalankan tradisi itu. Kiichiro berharap dapat menggunakan otak dan keahlian Jepang untuk membangun industry mobil di Jepang dan membuat mobil penumpang kecil kelas dunia. Kendati impiannya tidak terwujud selama era Kiichiro, sepupunya Eiji mewujudkannya melalui Corolla. Namun, jika mereka sudah puas dengan hal itu, Toyota akan berakhir sebagai pabrikan mobil murah Eiji menetapkan tujuan baru "Global Ten”, atau meraih 10\% penjualan global. Perlu waktu dua decade untuk mewujudkan hal itu. Setelah mencapai Global Ten, Toyota dengan berani menyatakan bahwa perusahaan akan meningkatkan pangsa pasar menjadi 15\% pada 2010. Angka $15 \%$ adalah setara dengan produsen otomotif terbesar di dunia. Di saat yang sama, agar tidak dilihat sebagai perusahaan dominan, Toyota menyusun konsep “kebaikan perusahaan” atau memperoleh penghargaan social dan cepat merespons isu pemanasan global degan membuat kendaraan listrik-hibrid. Berkat merek mewah Lexus, citra Toyota berubah dramatis dan memicu pertumbuhan lebih lanjut. ( Masaaki sato, 2008)

Kutipan di atas yang diambil dari buku "The Toyota Leaders" mungkin merupakan jawaban mengapa selama ini Toyota mampu menjadi raja dalam industry 
otomotif. Toyota, lebih dari sebuah perusahaan otomotif, tapi merupakan sebuah gaya hidup, sebuah pembuktian pemanfaatan perkembangan teknologi. Toyota juga cepat tanggap dalam menghadapi isu pemanasan global, oleh sebab itu dengan tingkat inovasi mereka yang tinggi, mobil-mobil hybrid diciptakan seperti Toyota Prius. Kehebatan Toyota terletak pada kombinasi kuantitas produk yang dijaga dengan kualitas.

\section{CONCLUSION}

Industri otomotif saat ini berkembang sangat pesat terutama di kota-kota besar, hal ini mengingat kebutuhan alat dalam menjalani kegiatan sehari-hari dengan mobilitas yang sangat tinggi. Brand yang bersaing dalam industry ini juga tidak sedikit, mulai dari kelas premium seperti Mercedes-benz, BMW sampai dengan Honda, Toyota, Daihatsu, dll. Belum lagi Brand baru yang masuk dalam persaingan industry otomotif seperti Proton dan Chery.

Industri otomotif memegang peranan penting dalam perekonomian terutama di Indonesia. Saat terjadi krisis global yang berasal dari Amerika pada tahun 2008, industri otomotif bertumbuh positif ketika industri-industri lainnya melambat. Pada pertengahan tahun 2009, industri otomotif di Indonesia kembali bersemangat sehingga penjualan dipastikan terus meningkat dari tahun ke tahun. Sampai pada akhir tahun 2010 penjualan mobil telah mencapai 625ribu unit, mengalahkan rekor pada tahun 2008 angka penjualannya mencapai 603unit. Indonesia bersama Thailand merupakan pasar industry otomotif dalam kawasan ASEAN. Tahun 2008, Thailand menguasai $29 \%$ penjualan mobil di ASEAN, kemudian diikuti Indonesia yang menguasai 28\% pasar. (Investor Daily, 2011) 
Mayoritas pasar otomotif di Indonesia dikuasai oleh mobil berpenumpang atau yang sering kita sebut multi purpose vehicle (MPV), MPV menguasai $75 \%$ penjualan mobil di Indonesia, sisanya adalah mobil seperti sedan dan city car. Berdasarkan Brand, Toyota merupakan market leader dengan menguasai 37,9\% pasar mobil di Indonesia, diikuti Daihatsu 14,7\% dan Mitsubishi 14,1\% pasar mobil. Dalam iklim persaingan industry otomotif seperti ini, Toyota mampu menjadi market leader, hal ini tentu bukan hal yang biasa. PT. Toyota Astra Motor melalui produk Toyota kijang meraih penghargaan indonesian customer loyalty award 2005 untuk kategori mobil non sedan berdasarkan survey indonesian customer loyalty index 2005 .

"Rahasia kekuatan Toyota adalah bahwa perusahaan memiliki strategi yang andal sejak awal, dan lebih penting lagi, pergantian generasi manajemen senior terus menjalankan tradisi itu. Kiichiro berharap dapat menggunakan otak dan keahlian Jepang untuk membangun industry mobil di Jepang dan membuat mobil penumpang kecil kelas dunia. Kendati impiannya tidak terwujud selama era Kiichiro, sepupunya Eiji mewujudkannya melalui Corolla. Namun, jika mereka sudah puas dengan hal itu, Toyota akan berakhir sebagai pabrikan mobil murah Eiji menetapkan tujuan baru "Global Ten”, atau meraih 10\% penjualan global. Perlu waktu dua decade untuk mewujudkan hal itu. Setelah mencapai Global Ten, Toyota dengan berani menyatakan bahwa perusahaan akan meningkatkan pangsa pasar menjadi $15 \%$ pada 2010. Angka $15 \%$ adalah setara dengan produsen otomotif terbesar di dunia. Di saat yang sama, agar tidak dilihat sebagai perusahaan dominan, Toyota menyusun konsep “kebaikan perusahaan” atau memperoleh penghargaan social dan cepat merespons isu pemanasan global degan membuat kendaraan listrik-hibrid. Berkat merek mewah Lexus, citra Toyota berubah dramatis dan memicu pertumbuhan lebih lanjut. ( Masaaki sato, 2008)

Kutipan di atas yang diambil dari buku "The Toyota Leaders" mungkin merupakan jawaban mengapa selama ini Toyota mampu menjadi raja dalam industry 
otomotif. Toyota, lebih dari sebuah perusahaan otomotif, tapi merupakan sebuah gaya hidup, sebuah pembuktian pemanfaatan perkembangan teknologi. Toyota juga cepat tanggap dalam menghadapi isu pemanasan global, oleh sebab itu dengan tingkat inovasi mereka yang tinggi, mobil-mobil hybrid diciptakan seperti Toyota Prius. Kehebatan Toyota terletak pada kombinasi kuantitas produk yang dijaga dengan kualitas.

\section{DISCUSSION}

Industri otomotif saat ini berkembang sangat pesat terutama di kota-kota besar, hal ini mengingat kebutuhan alat dalam menjalani kegiatan sehari-hari dengan mobilitas yang sangat tinggi. Brand yang bersaing dalam industry ini juga tidak sedikit, mulai dari kelas premium seperti Mercedes-benz, BMW sampai dengan Honda, Toyota, Daihatsu, dll. Belum lagi Brand baru yang masuk dalam persaingan industry otomotif seperti Proton dan Chery.

Industri otomotif memegang peranan penting dalam perekonomian terutama di Indonesia. Saat terjadi krisis global yang berasal dari Amerika pada tahun 2008, industri otomotif bertumbuh positif ketika industri-industri lainnya melambat. Pada pertengahan tahun 2009, industri otomotif di Indonesia kembali bersemangat sehingga penjualan dipastikan terus meningkat dari tahun ke tahun. Sampai pada akhir tahun 2010 penjualan mobil telah mencapai 625ribu unit, mengalahkan rekor pada tahun 2008 angka penjualannya mencapai 
603unit. Indonesia bersama Thailand

merupakan pasar industry otomotif

dalam kawasan ASEAN. Tahun

2008, Thailand menguasai 29\%

penjualan mobil di ASEAN,

kemudian diikuti Indonesia yang

menguasai $28 \%$ pasar. (Investor

Daily, 2011)

\section{E. REFERENCE}

[1] O. M. Febriani and A. S. Putra, "Sistem Informasi Monitoring Inventori Barang Pada Balai Riset Standardisasi Industri Bandar Lampung," J. Inform., vol. 13, no. 1, pp. 90-98, 2014.

[2] A. S. Putra, "Paperplain: Execution Fundamental Create Application With Borland Delphi 7.0 University Of Mitra Indonesia," 2018.

[3] A. S. Putra, "2018 Artikel Struktur Data, Audit Dan Jaringan Komputer," 2018.

[4] A. S. Putra, "ALIAS MANAGER USED IN DATABASE DESKTOP STUDI CASE DB DEMOS."

[5] A. S. Putra, "COMPREHENSIVE SET OF PROFESSIONAL FOR DISTRIBUTE COMPUTING."

[6] A. S. Putra, "DATA ORIENTED RECOGNITION IN BORLAND DELPHI 7.0."

[7] A. S. Putra, "EMBARCADERO
DELPHI XE 2 IN GPUPOWERED FIREMONKEY APPLICATION."

[8] A. S. Putra, "HAK ATAS KEKAYAAN INTELEKTUAL DALAM DUNIA TEKNOLOGY BERBASIS REVOLUSI INDUSTRI 4.0."

[9] A. S. Putra, "IMPLEMENTASI PERATURAN

PERUNDANGAN UU. NO 31 TAHUN 2000 TENTANG DESAIN INDUSTRI BERBASIS INFORMATION TECHNOLOGY."

[10] A. S. Putra, "IMPLEMENTATION OF PARADOX DBASE."

[11] A. S. Putra, "IMPLEMENTATION OF TRADE SECRET CASE STUDY SAMSUNG MOBILE PHONE."

[12] A. S. Putra, "IMPLEMENTATION PATENT FOR APPLICATION WEB BASED CASE STUDI WWW. PUBLIKLAMPUNG. COM."

[13] A. S. Putra, "IMPLEMENTATION SYSTEM FIRST TO INVENT IN DIGITALLY INDUSTRY."

[14] A. S. Putra, "MANUAL REPORT \& INTEGRATED DEVELOPMENT ENVIRONMENT BORLAND DELPHI 7.0."

[15] A. S. Putra, "PATENT AS RELEVAN SUPPORT RESEARCH."

[16] A. S. Putra, "PATENT FOR RESEARCH STUDY CASE OF APPLE. Inc."

[17] A. S. Putra, "PATENT 
PROTECTION

FOR

APPLICATION INVENT."

[18]

A. S. Putra, "QUICK REPORT

IN

PROPERTY

PROGRAMMING."

[19] A. S. Putra, "REVIEW CIRCUIT LAYOUT COMPONENT

REQUIREMENT ON ASUS NOTEBOOK."

[20] A. S. Putra, "REVIEW TRADEMARK PATENT FOR INDUSTRIAL

TECHNOLOGY BASED 4.0."

[21] A. S. Putra, "TOOLBAR COMPONENT PALLETTE IN OBJECT ORIENTED PROGRAMMING."

[22] A. S. Putra, "WORKING DIRECTORY SET FOR PARADOX 7."

[23] A. S. Putra, "ZQUERY CONNECTION

IMPLEMENTED

PROGRAMMING

STUDI

CASE PT. BANK BCA Tbk."

[24] A. S. Putra, D. R. Aryanti, and I. Hartati, "Metode SAW (Simple Additive Weighting) sebagai Sistem Pendukung Keputusan Guru Berprestasi (Studi Kasus: SMK Global Surya)," in Prosiding Seminar Nasional Darmajaya, 2018, vol. 1, no. 1, pp. 85-97.

[25] A. S. Putra and O. M. Febriani, "Knowledge Management Online Application in PDAM Lampung Province," in Prosiding International conference on Information Technology and Business (ICITB), 2018, pp. 181-187.

[26] A. S. Putra, O. M. Febriani, and B. Bachry, "Implementasi
Genetic Fuzzy System Untuk Mengidentifikasi Hasil Curian Kendaraan Bermotor Di Polda Lampung," SIMADA (Jurnal Sist. Inf. dan Manaj. Basis Data), vol. 1, no. 1, pp. 21-30, 2018.

[27] A. S. Putra, H. Sukri, and K. Zuhri, "Sistem Monitoring Realtime Jaringan Irigasi Desa (JIDES) Dengan Konsep Jaringan Sensor Nirkabel," IJEIS (Indonesian J. Electron. Instrum. Syst., vol. 8, no. 2, pp. 221-232.

[28] D. P. Sari, O. M. Febriani, and A. S. Putra, "Perancangan Sistem Informasi SDM Berprestasi pada SD Global Surya," in Prosiding Seminar Nasional Darmajaya, 2018, vol. 1, no. 1, pp. 289-294. 